\title{
Effects of ripeness and extraction conditions on the content of phenolic compounds in banana peels (Musa paradisiaca $\mathbf{L}$.)
}

\author{
${ }^{1}$ Pham, T.B.N., ${ }^{2}$ Nguyen, V.M., ${ }^{3,4}$ Pham, N.T.D., ${ }^{2, *}$ Tran, T.T. and ${ }^{3,4, *}$ Pham, T.N. \\ ${ }^{1}$ College of Engineering Technology, Can Tho University, Can Tho City, Vietnam \\ ${ }^{2}$ College of Agriculture, Can Tho University, Can Tho City, Vietnam \\ ${ }^{3}$ Faculty of Environmental and Food Engineering, Nguyen Tat Thanh University, Ho Chi Minh City, \\ Vietnam \\ ${ }^{4}$ Institute of Applied Technology and Sustainable Development, Nguyen Tat Thanh University, Ho Chi Minh \\ City, Vietnam
}

\author{
Article history: \\ Received: 3 March 2021 \\ Received in revised form: 6 \\ April 2021 \\ Accepted: 13 June 2021 \\ Available Online: 5 February \\ 2022
}

Keywords:

Antioxidant activity, Banana peel,

Extraction,

Maturity stages,

Polyphenol

DOI:

https://doi.org/10.26656/fr.2017.6(1).152

\begin{abstract}
The banana peels accounts for approximately $36 \%$ of the total fruit weight yet are mostly discarded as waste or used only for animal feeding. However, studies have shown that this by-product is rich in phenolic compounds and is a traditional treatment. The levels and composition of phenolic compounds are influenced by various factors. The purpose of the present study was to evaluate the effect of ripeness and extraction conditions on polyphenol content and antioxidant activity of banana peels (Musa paradisiaca L.) by analysing the total phenolic content (TPC) and using 2,2-diphenyl-1-picrylhydrazyl (DPPH) radical scavenging assays. Results have shown that yellowish green coloured banana peels exhibited significantly higher antioxidant activity as compared to mature (green-coloured) and ripe (yellow-coloured) peels. The optimal extraction conditions include ethanol concentration of $50 \%$, material/solvent ratio of $1: 40(\mathrm{w} / \mathrm{v})$, extraction time of $1.5 \mathrm{hrs}$ and temperature of $60^{\circ} \mathrm{C}$. Under these conditions, the obtained TPC and the antioxidant activity was approximately $9.93 \mathrm{mg} \mathrm{GAE} / \mathrm{g}$ and $50 \mu \mathrm{mol} \mathrm{TE} / \mathrm{g}$, respectively. Quantitative results by HPLC indicate the presence of quercetin-3-glc, vanillic acid, caffeic acid, ferulic acid, gallic acid and epicatechin.
\end{abstract}

\section{Introduction}

During the last few decades, the application of natural compounds with biological activities has been the subject that captures scientists' and social awareness (Andrs-Lacueva et al., 2009). Approximately half of the currently used pharmaceutical products are sourced directly or indirectly from products of natural origin, especially plants (Gohil et al., 2010; Arif and Fareed, 2011; Veeresham, 2012; Smeriglio et al., 2016; Jannat et al., 2019). Antioxidants, such as polyphenols, are widely used in many aspects of life. These compounds are commonly found in all parts of the plants and agricultural products (vegetables and cereals), playing an essential role in the organoleptic properties of foods (Haminiuk et al., 2012). The research on the acquisition and application of polyphenol compounds has been exploited on medicinal plants such as red gobs (Nguyen et al., 2018), and many other plants grown in Vietnam (Thu et al., 2004; Mai et al., 2007; Nguyen et al., 2016; Nguyen et al., 2019). However, due to the lack of an effective recycling scheme, the by-products of plants used for polyphenols extraction are mostly discarded as wastes, causing a tremendous burden to the environment and production cost. In this regard, one of the typical examples in Vietnam is banana peel.

Bananas are a popular and heavily used crop in Vietnam. In addition to daily use as a dessert, bananas are also used as a raw material for the production of various domestic and export goods. For example, Siamese bananas are widely grown to provide materials for making baked and dried products. The development of this industry disposes of a significant amount of banana peels, accounting for approximately $36 \%$ of the total weight of the fruit (Rebello et al., 2014). However, previous studies have shown that this is a valuable source of phenolic compounds with high antioxidant and antibacterial activities (Cai et al., 2004; Anhwange et al., 2008, Chabuck et al., 2013). Hellendoorn et al. (2011) determined the presence of phenolic compounds from the peel of nine different bananas grown in India and its 
antioxidant capacity. Kapadia et al. (2015) also demonstrated the banana's antimicrobial resistance. Extraction of polyphenols from Siamese banana peels would be the premise for the application of this source of polyphenols in the development of safe biological product lines while contributing to limiting waste polluting the environment and improving economic value for bananas. Studies on the acquisition of polyphenols from banana peels in Vietnam have also been interesting in recent times. However, the full investigation of suitable conditions for extracting polyphenols from banana peel sources in Vietnam in general and the Mekong Delta, in particular, has not been officially published.

Therefore, the initial study was carried out with the aim to determine the effect of ripeness of raw materials from Siamese banana peel and extraction conditions (by extraction method and liquid-solid extraction) that are suitable for obtaining polyphenols with high antioxidant activity.

\section{Materials and methods}

\subsection{Instruments}

Green sapodilla bananas at 3 different maturity levels were directly acquired at the banana orchards in An My commune, Ke Sach District, Soc Trang province, Vietnam to investigate polyphenol activity. The ripeness of the banana was selected based on TCVN 9687: 2013.

Matured Siamese banana peels were sampled at points of sale of baked bananas in a residential area of 91 B, Nguyen Van Linh Street, An Khanh Ward, Ninh Kieu District, Thanh Hoa. The banana peels were kept in a clean, cool place and collected samples within $1 \mathrm{hr}$ after peeling.

Tools and equipment: Thermostats (Memmert, Germany), vacuum rotary evaporators (Yamato BM510, Japan); optical measuring machine (Jinhua 722, China), oven (Shellab - CE3F -2, USA); Cold centrifuge (Hermle Z216MK, Germany), Colorimeter (NH300, China); Analytical balance 4 odd numbers (PA214 Ohaus, United States) and common analytical and laboratory instruments.

Chemicals: Ethanol, Folin - Ciaucalteu, DPPH (2,2 Diphenyl - 1 - picrylhydrazyl), gallic acid (Merck, Germany); Trolox (6-hydroxy-2,5,7,8tetramethylchroman-2-carboxylic acid) (Sigma, USA). Other chemicals of analytical standards are obtained from Merck (Germany).

\subsection{Research methods}

\subsubsection{Method of preparing banana peel powder}

After being brought to the laboratory, the banana peels were immediately subjected for preliminary removal of over-ripe, peeled pods, then washed again with clean water, chopped and dried at $50-55^{\circ} \mathrm{C}$ to almost constant mass (lower than 10\%) according to the sample preparation method of Fatemeh et al. (2012) and Rebello et al. (2014). The samples of dried banana peel powder were stored in vacuum PA packaging $(20 \mathrm{~g} / \mathrm{bag})$.

\subsubsection{Methods of analysis and identification of indicators}

Basic chemical criteria: humidity (\%); total protein $(\%)$; Total lipids $(\%)$, reducing sugars $(\%)$, ash (\%), carbohydrates $(\%)$ were determined based on AOAC 2005.

Total polyphenol content (TPC, \% GEA/g CKNL): Colorimetric method with gallic acid as standard. FolinCiocalteu reagent as an oxidant, determined at $738 \mathrm{~nm}$ (Siddiqua et al., 2010).

DPPH antioxidant activity (TEAC, $\mu \mathrm{mol} \mathrm{TE} / \mathrm{g}$ CKNL): Use a modified free radical determination method, with a reference material of DPPH (2,2Diphenyl-1-picrylhydrazyl) and Trolox, measured the colour change from violet to light yellow at $517 \mathrm{~nm}$ (Fatemeh et al., 2012).

\subsubsection{Extract polyphenols from banana peel pulp by extraction method}

The method of extracting polyphenols from banana peel powder and the extraction method according to Ehiowemwenguan et al. (2014). The sample $(20 \mathrm{~g})$ was soaked in a solvent with a suitable ratio, stirred with a magnetic stirrer (300 rpm) at a similar temperature and time to Ehiowemwenguan et al. (2014). After extraction, the sample was vacuum filtered, to remove the residues. The extract after filtration was centrifuged at $4^{\circ} \mathrm{C}, 4000$ rpm with an equal volume to analyse polyphenol content (TPC, mg GAE/g CKNL) and DPPH antioxidant activity (TEAC, $\mu \mathrm{mol} \mathrm{TE} / \mathrm{g}$ CKNL) in banana peel extract. The results are calculated on the dry matter content (CKNL).

\subsubsection{Methods of data collection and processing}

The experiments were randomly repeated 3 times, with 1 or 2 change factors. The results of the previous experiment were selected as a fixed parameter for the following experiments. Data were collected and processed by Statgraphics Centurion software 15.2. Analysis of variance (ANOVA) according to LSD test, Duncan to determine the difference between the mean of the treatments. 


\subsection{Experimental arrangement}

2.3.1 Determine the original composition of the raw material

The objective of the survey was to determine the chemical composition of the banana peel powder, and to know the moisture content of fresh ingredients and dried powders, as a basis to calculate the polyphenol content obtained in further experiments.

To determine the moisture content, the collected fresh banana peels were classified into 3 degrees of ripeness, cleaning and slicing treatment $(2-3 \mathrm{~mm})$. Then, the samples were finely ground analysed of the moisture content at three levels of ripeness.

Banana peels, after being dried, pulverized (BPF) according to the method described in Section 2.2.1, are used to conduct analysis of basic chemical criteria, including moisture (\%), total protein (\%), total lipid (\%), reducing sugar (\%), ash (\%) and carbohydrates (\%).

Sample weight/ripeness: Fresh sample: $50 \mathrm{~g} /$ sample $\times 3$ replicate $=150 \mathrm{~g}$; Dry powder sample: $50 \mathrm{~g} /$ sample $\times$ 3 iterations $=150 \mathrm{~g}$.

2.3.2 Effect of raw maturity on the acquisition of polyphenols from banana peel powder

The objective of the experiment was to change the polyphenol activity in banana peel powder corresponding to 3 different ripeness levels: Unripe (completely green skin); Mature maturity (green skin turns yellow) and fully ripened (completely yellow skin). The banana peel powder at three levels of ripeness was extracted by Ehiowemwenguan et al. (2014) are presented in section 2.2.3. In this survey, the extraction solvent was distilled water, the ratio of material and water was 1:10 (w/v), stirred by magnetic stirrer $(300 \mathrm{rpm})$ at room temperature $\left(28-30^{\circ} \mathrm{C}\right)$ for a period of $3 \mathrm{hrs}$. Based on the results of the survey, the degree of change of polyphenol content according to each maturity of the raw material, thereby selecting the appropriate ripeness for the next study.

\subsubsection{Conditions for extracting polyphenols from banana peel powder}

Factors affecting the efficiency of polyphenol collection from banana peel powder were investigated one after another. For each sample tested, $20 \mathrm{~g}$ of banana peel with appropriate ripeness (from the survey in section 2.3.2) was selected and used to extract polyphenols by extraction method (described in section 2.2.3).

The effect of the ratio of banana peel powder and extraction solvent was studied using distilled water as solvent at various ratios from $1: 5 ; 1: 10 ; 1: 20 ; 1: 30 ; 1: 40$ and 1:50 (w/v, g/mL) within $3 \mathrm{hrs}$ at room temperature condition $\left(28-30^{\circ} \mathrm{C}\right)$.

Based on the ripeness of appropriate banana peels, the proportion of materials and solvents was selected to investigate the effects of ethanol concentration on the efficiency of polyphenol extraction. In this experiment, distilled water was replaced with ethanol at concentrations ranging from $0,10,30,50,70$ and $90 \%$ at similar temperature conditions and extraction time (28$30^{\circ} \mathrm{C}$ and $3 \mathrm{hrs}$, respectively).

The interaction of temperature and extraction time with the extraction method that affects the ability to receive polyphenols was investigated. In this experiment, the extraction process was adjusted to 5 levels of temperature (from $30^{\circ} \mathrm{C}$ to $70^{\circ} \mathrm{C}$ ) and 7 levels of extraction time (from 30 mins to $3.5 \mathrm{hrs}$ ). From a temperature of $40^{\circ} \mathrm{C}$, a circulating extraction system was used to help limit solvent loss.

\section{Results and discussion}

\subsection{Chemical composition of raw materials}

The moisture content of fresh banana peels at 3 maturity levels was determined, and the basic chemical composition of the banana peel pulp is used as the basis for extraction and polyphenols. The results are presented in Table 1.

Survey results show that the moisture content of fresh banana skin is very high and varied between the three levels of ripeness. Of all banana peel samples, the green banana skin had the highest moisture content $(90.05 \%)$, followed by the yellow-green fruit $(88.16 \%)$ and completely ripe fruit $(81.12 \%)$. The results obtained are almost similar to the moisture analysis results of the same kind of fresh bananas according to the study of Aboul-Enein (2016). With high moisture content, the banana peels are quickly damaged, and the large moisture content makes the difference in concentration between the two phases decrease, preventing the solvent's movement from penetrating deeply into the material, slowing down the amplification process. The solute molecules dispersed into solvents and consequently reduced the rate of the extraction process, which takes a long time of thermal action to acquire polyphenols. Besides, fresh raw materials with high moisture content will reduce the concentration of selected extraction solvent, affecting extraction efficiency. Therefore, it is necessary to separate the type of moisture in the banana skin, producing banana peel powder with suitable moisture content. This is also a condition for sample homogenization.

The preparation of the banana peel powder is carried 
Table 1. Results of chemical composition analysis of Siamese banana peel powder

\begin{tabular}{|c|c|c|c|}
\hline \multirow{2}{*}{ Ingredient } & \multicolumn{3}{|c|}{ Level of ripeness (indicated by the banana peel color) } \\
\hline & Completely green & Yellowish green & Bright yellow \\
\hline Moisture of fresh banana peel (\%) & $90.05 \pm 0.54^{\mathrm{c}}$ & $88.16 \pm 0.17^{\mathrm{b}}$ & $81.12 \pm 1.12^{\mathrm{a}}$ \\
\hline Moisture of Siamese Banana Powder (\%) & $8.12 \pm 0.67^{\mathrm{b}}$ & $7.15 \pm 0.16^{\mathrm{a}}$ & $7.65 \pm 0.32^{\mathrm{ab}}$ \\
\hline \multicolumn{4}{|c|}{ The chemical composition of banana peel powder } \\
\hline Protein (\%cbk) & $10.17 \pm 0.56^{\mathrm{ab}}$ & $11.73 \pm 0.45^{\mathrm{c}}$ & $9.33 \pm 0.37^{\mathrm{a}}$ \\
\hline Lipid (\%cbk) & $14.26 \pm 0.48^{\mathrm{a}}$ & $16.37 \pm 0.66^{\mathrm{ac}}$ & $17.11 \pm 0.52^{\mathrm{c}}$ \\
\hline Carbohydrate (\%cbk) & $62.91 \pm 2.13^{\mathrm{a}}$ & $60.92 \pm 1.86^{\mathrm{a}}$ & $62.39 \pm 1.78^{\mathrm{a}}$ \\
\hline Ash $(\%$ cbk $)$ & $12.63 \pm 0.67^{\mathrm{c}}$ & $10.93 \pm 0.42^{\mathrm{a}}$ & $11.06 \pm 0.44^{\mathrm{ab}}$ \\
\hline
\end{tabular}

Values are presented as mean \pm SD. Values with different superscript within the same row are significantly different according to the LSD test at $95 \%$ confidence.

out by drying the material at a temperature of $50^{\circ} \mathrm{C}$ to a nearly constant reduction in mass to transfer to grinding, homogenizing samples and refrigerating, dark packaging to prevent the destruction of polyphenols. The drying of raw materials also contributes to the inactivation of the enzyme polyphenol oxidase and helps to preserve raw materials in the long run. Results of moisture analysis of the pulp made from banana peel powder showed that the moisture content of the dried banana pulp could be reduced to values of 7 to $8 \%$, lower than $10 \%$ as recommended, namely moisture of green Siamese banana peel powder is $8.12 \pm 0.67 \%$, yellowish-green Siamese banana peel powder is $7.15 \pm 0.16 \%$ and for cases of fully ripe banana peel is $7.65 \pm 0.32 \%$. Green banana peels have a high initial moisture content, hardshell structure, and difficult moisture drainage, so it is difficult to lower the humidity below $8 \%$ as in the case of yellow and yellowish green banana peels. Prolonged drying time can cause the reduction of bioactive substances that are easily oxidized in banana peels (Toor and Savage, 2006). This is the parameter used to calculate the polyphenol content and activity obtained in subsequent surveys.

In terms of chemical composition, the analysis results showed that the protein content (calculated on the dry matter content) of the banana peel powder is quite high and there is an irregular fluctuation between 3 levels of ripeness, with the value corresponding to the ripeness from green to yellowish-green and completely yellow is $10.17 \% ; 11.73 \%$ and $9.33 \%$, respectively. There are not many studies on the changes of chemical composition in banana peel powder to explain the fluctuation of protein as well as other components according to maturity level. However, the study of Romelle et al. (2016) also found that the protein fluctuation range in banana skin is $10.44 \pm 0.38 \%$ (calculated on the dry matter content). One of the rare studies on the nutritional content of banana peels according to the different ripeness of Tartrakoon et al. (1999) only showed that at the three levels of the nine surveyed are green, almost nine and nine have a change in decreasing moisture content, and the protein content (not explicitly mentioned is the result determined on the total mass amount of ingredients or only on dry matter content) corresponding to 3 levels of ripeness is 5.19; 6.61 and $4.77 \%$ - the same variation as the survey results. In general, the protein content is high, so the interaction between protein and polyphenols is inevitable. Polyphenols are known to make complexes with proteins, resulting in changes in the structural, functional and nutritional properties of both compounds. These interactions are not covalent bonds, but hydrophobic interactions that are sustained by hydrogen bonds (Yuksel et al., 2010). A surprising result is that the lipid content in banana peel pulp is high, accounting for 14.26 to $17.11 \%$ of CKNL so it may also be an adverse cause for the extraction of polyphenols. The data collected are consistent with the research of Tartrakoon et al. (1999) - outstandingly high lipid content, more than double the value when compared to protein (10.66 to $14.56 \%$ and increases with the maturity of the banana skin) (Tartrakoon et al., 1999). However, the study of Romelle et al. (2016) found only about $8.4 \%$ of the lipid is present in a banana skin. However, these results also indicate that it is important to note that the presence of relatively high concentrations of lipids in banana peel powder will have an impact on the extraction process and affect solvent concentration (Fatemeh et al., 2012). Occupying a sizable part of the banana peel powder is carbohydrates (60.92 to $62.91 \%)$. Many studies have demonstrated the interaction between polyphenols and carbohydrates such as those of Le Bourvellec et al. (2009) and Padayachee et al. (2012), mainly hydrophobic interactions, covalent bonds and hydrogen bonds (the link between the $\mathrm{OH}$ group of polyphenols and oxygen atoms in glycoside bonds of polysaccharides). From the results of the analysis, it is necessary to select the ripeness of the banana peel appropriately to improve the effectiveness of extraction and acquisition of polyphenols highly effective.

\subsection{Effect of ripeness of materials}

The ripeness of the starting material is the major 
factor affecting the acquisition of polyphenols as well as other biological compounds. The results obtained in Table 2 show that the highest polyphenol extraction efficiency at yellow-green maturity reached $1.55 \mathrm{mg}$ GAE/g CKNL which is 2 to 3 times higher than the remaining maturity and antioxidant activity (the ability to trap free radicals DPPH was similar to reach $16.91 \pm 0.345 \mu \mathrm{mol}$ TE/g CKNL.

Table 2. Changes in the polyphenol TPC content and antioxidant activity according to raw material maturity

\begin{tabular}{ccc}
\hline \multirow{2}{*}{ Ripeness } & $\begin{array}{c}\text { Total polyphenols } \\
(\text { TPC })\end{array}$ & $\begin{array}{c}\text { Antioxidant activity } \\
\text { (TEAC) }\end{array}$ \\
\cline { 2 - 3 }$(\mathrm{mg} \mathrm{GAE} / \mathrm{g} \mathrm{CKNL})$ & $(\mu \mathrm{mol} \mathrm{TE} / \mathrm{g} \mathrm{CKNL})$ \\
\hline Green & $0.77 \pm 0.02^{\mathrm{b}}$ & $12.23 \pm 0.311^{\mathrm{b}}$ \\
Yellowish green & $1.55 \pm 0.08^{\mathrm{a}}$ & $16.91 \pm 0.345^{\mathrm{a}}$ \\
Bright yellow & $0.51 \pm 0.02^{\mathrm{c}}$ & $6.27 \pm 0.498^{\mathrm{c}}$ \\
\hline
\end{tabular}

Values are presented as mean \pm SD. Values with different superscript within the same row are significantly different according to the LSD test at $95 \%$ confidence.

Values with different accompanying letters in the same row represent statistically significant differences according to the LSD test at $95 \%$ confidence. The values shown in the table are the average of 3 replicates.

In many fruits, antioxidant activity depends on polyphenol content. Research by Gruz et al. (2011) on tea tree fruit showed that antioxidant capacity depends on polyphenol content. In general, the correlation between polyphenol content and antioxidant activity is quite linearly correlated. This suggests that polyphenol compounds may play a major role in the antioxidant activity of each maturity.

This has practical implications for the selection of maturity level (yellowish-green skin) as the starting material for further studies. The recovery of banana peel by-products for the acquisition of polyphenol and the use of polyphenols for the food and medicine industries should be considered.

\subsection{Effect of material and solvent ratio}

The effect of the ratio of material and solvent (w/v) on the extraction efficiency of polyphenols from banana peel powder at maturity (yellowish-green skin) is shown in Figure 1.

The results showed that the efficiency of extracting polyphenols from banana peel powder reached the highest at the ratio of materials and solvent used was $1: 50(\mathrm{w} / \mathrm{v})$, the total polyphenol content was $3.48 \mathrm{mg}$ GAE/g CKNL, higher than the ratio $1: 10$ by 2.7 times. In parallel, antioxidant activity also increased as the extraction solvent increased. At the ratio of banana peel and the solvent ratio of 1:40 (w/v) and 1:50 (w/v), the antioxidant activity was not much different (e.g. $18.97 \pm 1.32 \mu \mathrm{mol}$ TE/g CKNL and $20.81 \pm 1.37 \mu \mathrm{mol} \mathrm{TE} /$ g CKNL, respectively). In addition, the polyphenol content obtained when extracting banana peel powder with water at the ratio of 1:40 $(\mathrm{w} / \mathrm{v})$ and 1:50 $(\mathrm{w} / \mathrm{v})$ was not significantly different. As the amount of extracted water continued to increase, the amount of polyphenols obtained did not increase but tended to be asymptotic.

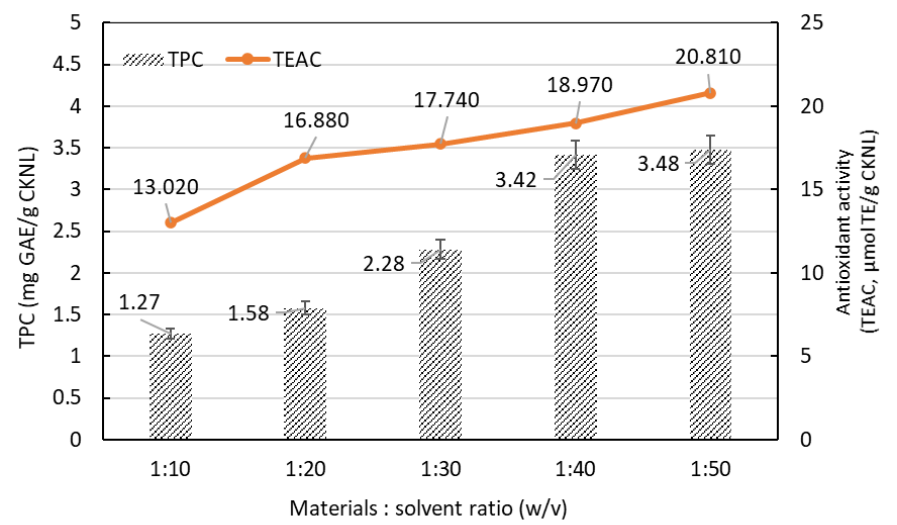

Figure 1. Effect of proportion of materials and solvents (distilled water) (w/v) on the efficiency of polyphenol extraction from banana peels.

According to Kossah et al. (2010), the relationship between TPC and DPPH is quite complicated, not following any rules. The amount of solvent is too low, which is not enough to motivate the process of osmosis, diffusion into raw materials, the extraction compounds are not completely dissolved into the solvent, making it difficult for the filtration process and leading to low extraction efficiency. In addition, the higher the amount of solvent, the greater amount of oxygen dissolved into the solvent. Therefore, the presence of oxygen in the air weakens the antioxidant activity of polyphenols. Moreover, the process of dissolving biological substances into solvents is a physical process. The increasing amount of solvent enhances the permeability of biologically active substances. When the ratio of solvent and material is large, the difference in concentration between solvent and solute becomes larger. Therefore, many bioactive substances are soluble if more water is used (Cacace and Mazza, 2003). This shows that selecting the right ratio of materials and solvents not only enhances the efficiency of TPC acquisition but also helps minimize the waste of solvents to save costs. Therefore, a ratio of 1:40 (w/v) between banana peel material and solvent was chosen as a fixed factor for further research.

\subsection{Effect of concentration of ethanol}

Ethanol was used in the experiment as a solvent because of its non-toxic properties. It was also a commonly used solvent in extracting polyphenols from 
banana peel powder of Shengjiu et al. (2014). The results showed the clear effect of adjusting ethanol concentration on the efficiency of polyphenol acquisition and antioxidant activity of the extract. The total content of polyphenols from the pulp extract was shown in Figure 2. However, TPC tends to decrease when the concentration of ethanol increases to $70 \%$. The TPC change is similar to the change in the antioxidant capacity of the extract, in which the antioxidant activity reaches its maximum value $(31.29 \pm 1.44 \mu \mathrm{mol} \mathrm{TE} / \mathrm{g}$ CKNL) at the ethanol concentration of $50 \%$.

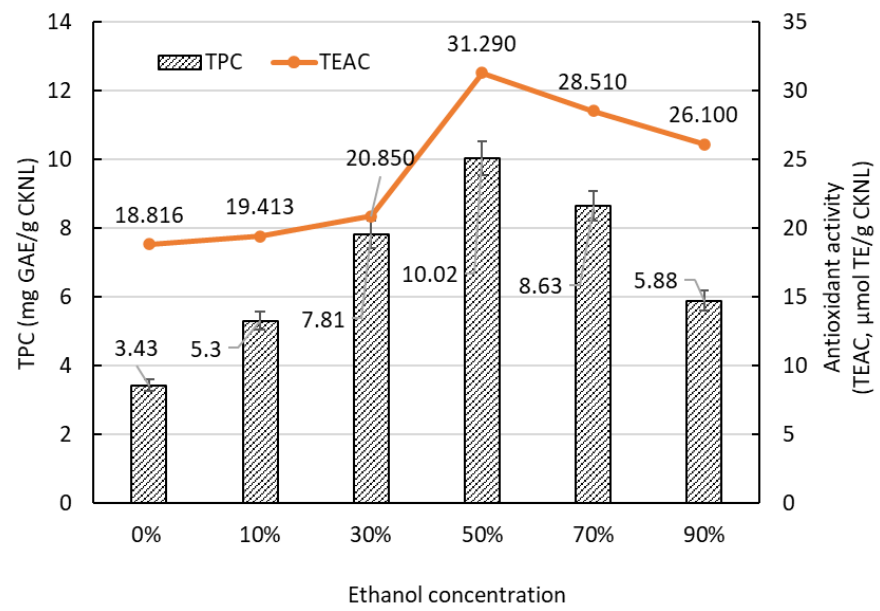

Figure 2. Effect of ethanol concentration (\%) on total polyphenol content TPC and antioxidant activity from banana peel extract.

Figure 3 shows the colour change of the extract obtained at different concentration levels. In addition to the increasing concentration of polyphenol content. The colour of the extract also changed from light brown to dark yellow when there is an increase in solvent concentration, which indicates that many undesirable compounds and chlorophyll were also extracted.

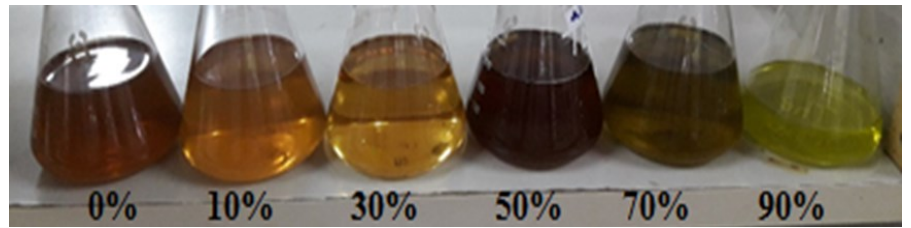

Figure 3. Colour change of polyphenol extract at ethanol concentrations.

The study of Shengjiu et al. (2014) also proposed using $50 \%$ ethanol to obtain polyphenols from banana peel pulp. Recent studies by Schmidt et al. (2015) also used $50 \%$ ethanol to extract polyphenols from dried flower and corn powders. Based on the results of the survey, $50 \%$ ethanol concentration is the most appropriate value to obtain polyphenols from the banana peel extract.

\subsection{The interaction effect of extraction temperature and time}

The appropriate value of the investigated factors was kept constant to investigate the effect of temperature and extraction time. The results from Table 3 show that the extraction efficiency increases very quickly when the temperature increases from $30^{\circ} \mathrm{C}$ to $60^{\circ} \mathrm{C}$. As the temperature continues to increase, the extraction efficiency tends to decrease (including TPC and TEAC) but at a slowly decreasing rate. From the results in Table 3 , the antioxidant capacity and TPC content reached the highest value (e.g. $50.02 \mu \mathrm{mol} \mathrm{TE} / \mathrm{g} \mathrm{CKNL}$ and $9.93 \mathrm{mg}$ GAE/g CKNL, respectively) at $60^{\circ} \mathrm{C}$ within $1.5 \mathrm{hrs}$. Research by Schmidt et al. (2015) also suggested using the temperature of $60^{\circ} \mathrm{C}$ and $50 \%$ ethanol for 30 mins to obtain polyphenols from flowers and corn. This shows that the conditions of extraction will depend on the type of material and are influenced by many external factors.

\subsection{Identification of bioactive compounds}

Using HPLC technique to quantify the presence of polyphenol compounds in the extract from Siamese banana peel powder. Survey results show that using a 50 $\mathrm{mg} / 10 \mathrm{~mL}$ solution of banana peel extract has identified the presence of Quercetin-3-glc., vanillic acid, 3-hydroxy benzoic acid, caffeic acid, ferulic acid based on the corresponding retention time. Details are shown in the annex in Figure 4.
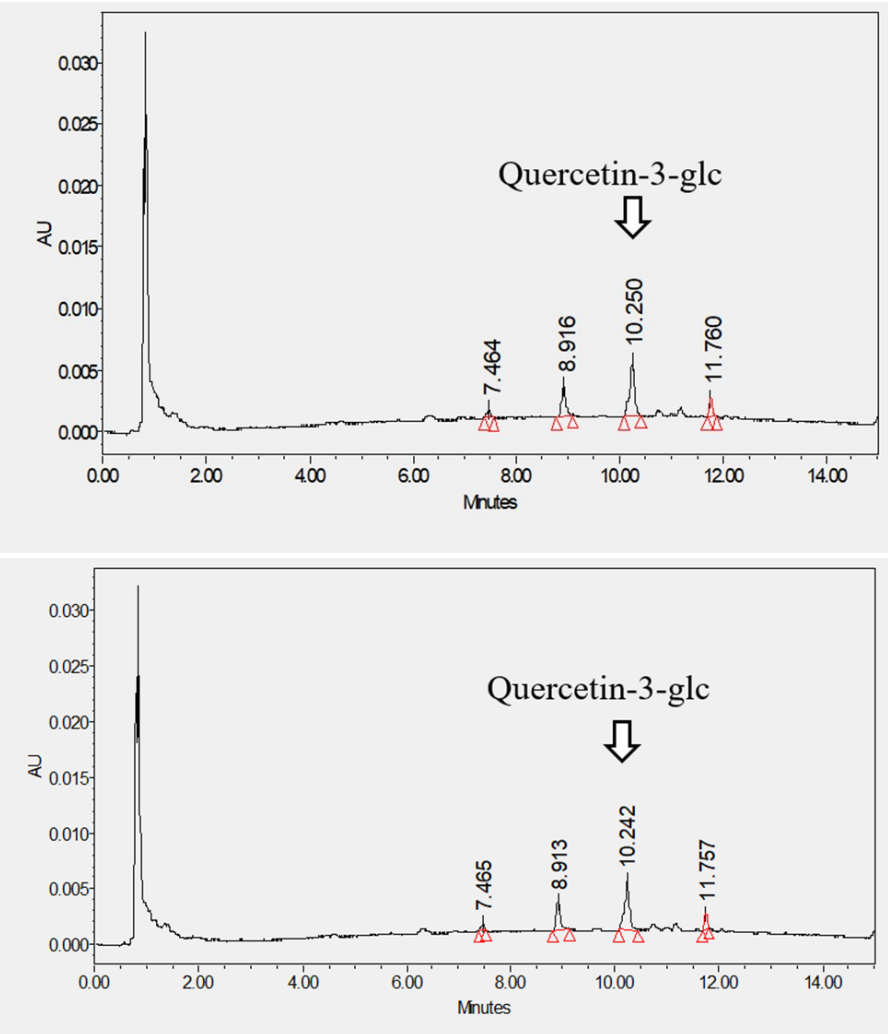

Figure 4. HPLC graphs determine the presence of flavonoids in banana peel extract at $360 \mathrm{~nm}$.

The content of polyphenol compounds was identified by comparing with the calibration graph of the change of polyphenol content of the corresponding standards 
Table 3. Changes in total polyphenol content and antioxidant activity of polyphenol extracts from banana peel powder due to the interaction of temperature and extraction time

\begin{tabular}{|c|c|c|c|}
\hline \multirow{2}{*}{ Temperature $\left({ }^{\circ} \mathrm{C}\right)$} & \multirow{2}{*}{ Time (hour) } & \multirow{2}{*}{$\frac{\text { Total polyphenol content }}{(\mathrm{mg} \mathrm{GAE} / \mathrm{g} \text { CKNL) }}$} & \multirow{2}{*}{$\frac{\text { Antioxidant activity }}{(\mu \mathrm{mol} \mathrm{TE} / \mathrm{g} \text { CKNL })}$} \\
\hline & & & \\
\hline \multirow{7}{*}{30} & 0.5 & $2.84 \pm 0.36^{\mathrm{a}}$ & $11.41 \pm 1.52^{\mathrm{a}}$ \\
\hline & 1.0 & $4.00 \pm 0.32^{\mathrm{b}}$ & $16.56 \pm 1.47^{\mathrm{b}}$ \\
\hline & 1.5 & $5.98 \pm 0.31^{\mathrm{def}}$ & $25.79 \pm 1.68^{\text {efg }}$ \\
\hline & 2.0 & $7.36 \pm 0.28^{\mathrm{hi}}$ & $30.93 \pm 2.01^{\mathrm{ijk}}$ \\
\hline & 2.5 & $8.14 \pm 0.33^{\mathrm{j}}$ & $31.95 \pm 1.72^{\mathrm{k}}$ \\
\hline & 3.0 & $8.31 \pm 0.32^{\mathrm{k}}$ & $28.87 \pm 1.31^{\mathrm{hij}}$ \\
\hline & 3.5 & $7.89 \pm 0.31^{\mathrm{ij}}$ & $21.68 \pm 1.43^{\mathrm{cd}}$ \\
\hline \multirow{7}{*}{40} & 0.5 & $4.31 \pm 0.38^{\mathrm{bc}}$ & $16.15 \pm 1.25^{\mathrm{b}}$ \\
\hline & 1.0 & $6.56 \pm 0.41^{\mathrm{fg}}$ & $28.55 \pm 1.41^{\mathrm{hij}}$ \\
\hline & 1.5 & $8.21 \pm 0.39^{\mathrm{jk}}$ & $36.84 \pm 1.77^{\mathrm{lm}}$ \\
\hline & 2.0 & $9.25 \pm 0.35^{\operatorname{lmn}}$ & $41.03 \pm 1.51^{\mathrm{op}}$ \\
\hline & 2.5 & $9.70 \pm 0.32^{\text {no }}$ & $41.12 \pm 1.52^{\mathrm{op}}$ \\
\hline & 3.0 & $9.54 \pm 0.36^{\mathrm{mno}}$ & $37.09 \pm 1.36^{\mathrm{lm}}$ \\
\hline & 3.5 & $8.78 \pm 0.28^{\mathrm{kl}}$ & $28.96 \pm 1.12^{\mathrm{hij}}$ \\
\hline \multirow{7}{*}{50} & 0.5 & $5.93 \pm 0.33^{\mathrm{de}}$ & $23.99 \pm 1.52^{\mathrm{de}}$ \\
\hline & 1.0 & $7.85 \pm 0.31^{\mathrm{ij}}$ & $35.46 \pm 1.23^{1}$ \\
\hline & 1.5 & $9.16 \pm 0.34^{1 \mathrm{lmn}}$ & $42.81 \pm 1.47^{\mathrm{opq}}$ \\
\hline & 2.0 & $9.68 \pm 0.41^{\text {no }}$ & $46.06 \pm 1.86^{\mathrm{rs}}$ \\
\hline & 2.5 & $9.79 \pm 0.42^{\text {no }}$ & $45.20 \pm 1.78^{\mathrm{qrs}}$ \\
\hline & 3.0 & $9.50 \pm 0.36^{\mathrm{mno}}$ & $40.23 \pm 1.51^{\mathrm{no}}$ \\
\hline & 3.5 & $8.41 \pm 0.32^{\mathrm{jk}}$ & $31.16 \pm 1.36^{\mathrm{jk}}$ \\
\hline \multirow{7}{*}{60} & 0.5 & $6.29 \pm 0.31^{\text {efg }}$ & $26.76 \pm 1.27^{\mathrm{fgh}}$ \\
\hline & 1.0 & $7.87 \pm 0.41^{\mathrm{ij}}$ & $37.28 \pm 1.33^{\mathrm{lm}}$ \\
\hline & 1.5 & $9.93 \pm 0.32^{\circ}$ & $50.02 \pm 1.87^{\mathrm{t}}$ \\
\hline & 2.0 & $9.53 \pm 0.28^{\mathrm{mno}}$ & $47.58 \pm 1.51^{\mathrm{s}}$ \\
\hline & 2.5 & $9.02 \pm 0.31^{1 \mathrm{~m}}$ & $44.19 \pm 1.46^{\mathrm{qr}}$ \\
\hline & 3.0 & $8.20 \pm 0.36^{\mathrm{jk}}$ & $38.29 \pm 1.42^{\mathrm{mn}}$ \\
\hline & 3.5 & $6.77 \pm 0.41^{\text {gh }}$ & $28.27 \pm 1.51^{\mathrm{ghi}}$ \\
\hline \multirow{7}{*}{70} & 0.5 & $4.74 \pm 0.28^{\mathrm{c}}$ & $24.44 \pm 1.22^{\mathrm{ef}}$ \\
\hline & 1.0 & $6.63 \pm 0.32^{\mathrm{g}}$ & $27.88 \pm 1.23^{\mathrm{gh}}$ \\
\hline & 1.5 & $7.28 \pm 0.34^{\mathrm{hi}}$ & $43.44 \pm 1.41^{\mathrm{pqr}}$ \\
\hline & 2.0 & $7.33 \pm 0.33^{\mathrm{hi}}$ & $40.85 \pm 1.39^{\mathrm{op}}$ \\
\hline & 2.5 & $6.78 \pm 0.35^{\mathrm{gh}}$ & $38.11 \pm 1.42^{1 \mathrm{mn}}$ \\
\hline & 3.0 & $5.62 \pm 0.31^{\mathrm{d}}$ & $31.26 \pm 1.36^{\mathrm{jk}}$ \\
\hline & 3.5 & $3.87 \pm 0.35^{\mathrm{b}}$ & $20.30 \pm 1.32^{\mathrm{c}}$ \\
\hline
\end{tabular}

Values are presented as mean \pm SD. Values with different superscript within the same column are significantly different according to the LSD test at $95 \%$ confidence.

Table 4. The polyphenol component is present in the banana peel extract

\begin{tabular}{lcccc}
\hline \multirow{2}{*}{ The polyphenol components } & $\begin{array}{c}\text { The order in the } \\
\text { chart }\end{array}$ & \multicolumn{2}{c}{ Time saved (minutes) } & $\begin{array}{c}\text { Concentration of ingredients } \\
\text { (mg/g dry extract)* }\end{array}$ \\
\cline { 3 - 4 } Quercetin-3-glc & $3 / \mathrm{H} 4.18$ & 10.424 & 10.25 & $0.5317 \pm 0.0071$ \\
p-Hydroxybenzoic acid & $2 / \mathrm{H} 4.19$ & 3.297 & 3.298 & $2.4685 \pm 0.0085$ \\
Ferulic acid & $4 / \mathrm{H} 4.19$ & 3.638 & 3.65 & $0.1525 \pm 0.0047$ \\
Caffeic acid & $5 / \mathrm{H} 4.19$ & 3.75 & 3.762 & $0.0702 \pm 0.0036$ \\
Vanillic acid & $8 / \mathrm{H} 4.19$ & 5.141 & 5.152 & $0.3484 \pm 0.0028$ \\
Total & & & & $2.5713 \pm 0.0040$ \\
\hline
\end{tabular}

* The result is calculated based on the corresponding calibration curve $\mathrm{y}=\mathrm{ax}+\mathrm{b}$ where $\mathrm{y}$ is the peak area, $\mathrm{x}$ is the content of the components $(\mathrm{mg} / \mathrm{mL})$, calculated on a $50 \mathrm{mg}$ sample of an extract high in $10 \mathrm{~mL} 80 \% \mathrm{MeOH}$ contains $1 \%$ formic acid. 
summarized in Table 4. In the composition of phenolic compounds, epicatechin was also detected at position 7 of Figure 5, yet it was not listed in Table 4 due to the lack of calibration curve equation.

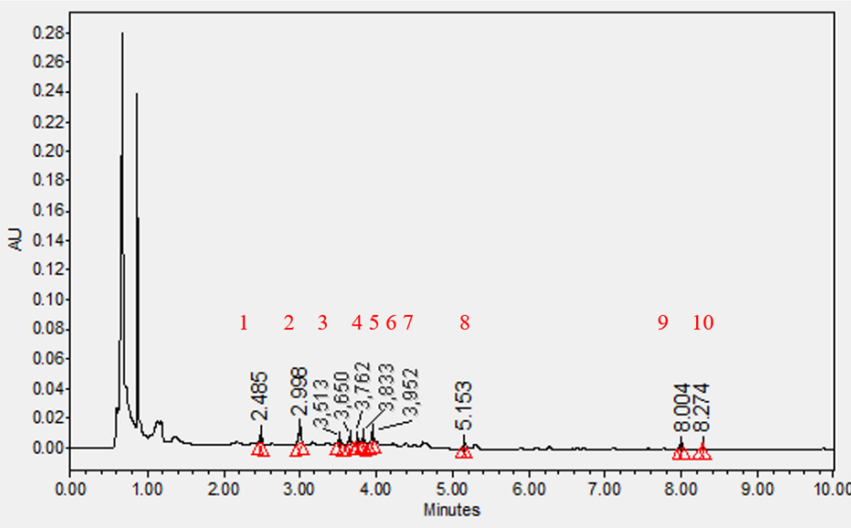

Figure 5. The HPLC graph identifies the presence of phenolic compounds in banana peel extract extracted at a wavelength of $280 \mathrm{~nm}$.

The results of measurement and analysis confirmed that the polyphenol extract from banana peel has the presence of bioactive flavonoid and phenolic components. However, the total concentration of the identified components is quite lower when compared to the total polyphenol content, which can be explained by the fact that many polyphenol compounds with biological activity have not been found yet. However, this result also contributes to confirming the feasibility of collecting polyphenols from the banana by-products and has the appropriate use for this extract.

\section{Conclusion}

Research has shown the viability of using a banana by-product source to obtain polyphenols. Siamese banana peel with a yellowish-green colour is suitable to carry out the extraction process of polyphenols. Extraction conditions of polyphenols by leaching method are achieved when using a 50\% ethanol solvent with a ratio of ingredients and solvents of 1:40 (w/v), extraction temperature $60^{\circ} \mathrm{C}$ during extraction $1.5 \mathrm{hrs}$. However, under these conditions, polyphenol content is still quite low, thus suggesting the use of supportive solutions such as microwave, ultrasound to shorten processing time and increase the recovery efficiency and antioxidant activity of polyphenols from banana peel powder.

\section{Conflict of interest}

The authors declare no conflict of interest.

\section{Acknowledgments}

This study was supported by grants from Nguyen Tat Thanh University, Ho Chi Minh City, Viet Nam.

\section{References}

Aboul-Enein, B. (2016). The mediterranean-style diet: Historical and contemporary perspectives. Journal of Nutritional Biology, 2(1), 73-74. https:// doi.org/10.18314/jnb.v2i1.102

Andrs-Lacueva, C., Medina-Remon, A., Llorach, R., Urpi-Sarda, M., Khan, N., Chiva-Blanch, G., Zamora -Ros, R., Rotches-Ribalta, M. and Lamuela-Ravents, R.M. (2009). Phenolic compounds: Chemistry and occurrence in fruits and vegetables. In de la Rosa, L.A., Alvarez-Parrilla, E. and Gonzlez-Aguilar, G.A. (Eds.). Fruit and Vegetable Phytochemicals, p. 5388. United Kingdom: Wiley-Blackwell. https:// doi.org/10.1002/9780813809397.ch2

Anhwange, B.A., Ugye, T.J. and Nyiaatagher, T.D. (2008). Chemical composition of Musa sapientum (banana) peels. Electronic Journal of Environmental, Agricultural and Food Chemistry, 8(6), 437-442.

Arif, M. and Fareed, S. (2011) Pharmacognostical studies and evaluation of total phenolic and flavonoid contents of traditionally utilized fruits of Solanum torvum sw. Indian Journal of Natural Products and Resources, 2(2), 218-224

Cacace, J.E. and Mazza, G. (2003). Optimization of extraction of anthocyanins from black currants with aqueous ethanol. Journal of Food Science, 68(1), 240-248. https://doi.org/10.1111/j.13652621.2003.tb14146.x

Cai, Y., Luo, Q., Sun, M. and Corke, H. (2004). Antioxidant activity and phenolic compounds of 112 traditional Chinese medicinal plants associated with anticancer. Life Sciences, 74(17), 2157-2184. https:// doi.org/10.1016/j.lfs.2003.09.047

Chabuck, Z.A.G., Al-Charrakh, A.H., Hindi, N.K.K. and Hindi, S.K.K. (2013). Antimicrobial Effect of Aqueous Banana Peel Extract, Iraq. Research Gate: Pharmaceutical Sciences, 1, 73-75

Ehiowemwenguan, G., Emoghene, A.O. and Inetianbor, J.E. (2014) Antibacterial and phytochemical analysis of Banana fruit peel. IOSR Journal of Pharmacy (IOSRPHR), 4(8), 18-25. $\quad$ https:// doi.org/10.9790/3013-0408018025

Fatemeh, S.R., Saifullah, R., Abbas, F.M.A. and Azhar, M.E. (2012). Total phenolics, flavonoids and antioxidant activity of banana pulp and peel flours: influence of variety and stage of ripeness. International Food Research Journal, 19(3), 10411046.

Gohil, K., Patel, J. and Gajjar, A. (2010). Pharmacological review on Centella asiatica: A potential herbal cure-all. Indian Journal of 
Pharmaceutical Sciences, 72(5), 546. https:// doi.org/10.4103/0250-474X.78519

Gruz, J., Ayaz, F.A., Torun, H. and Strnad, M. (2011). Phenolic acid content and radical scavenging activity of extracts from medlar (Mespilus germanica L.) fruit at different stages of ripening. Food Chemistry, 124(1), 271-277. https://doi.org/10.1016/ j.foodchem.2010.06.030

Haminiuk, C.W.I., Maciel, G.M., Plata-Oviedo, M.S.V. and Peralta, R.M. (2012). Phenolic compounds in fruits - an overview: Phenolic compounds in fruits. International Journal of Food Science and Technology, 47(10), 2023-2044. https:// doi.org/10.1111/j.1365-2621.2012.03067.x

Hellendoorn, J., De Schutter, B., Baskar, L.D. and Papp, Z. (2011). Traffic control and intelligent vehicle highway systems: A survey. IET Intelligent Transport Systems, 5(1), 38-52. https:// doi.org/10.1049/iet-its.2009.0001

Jannat, K., Rahman, T. and Rahmatullah, M. (2019). Traditional uses, phytochemicals and pharmacological properties of Allium tuberosum Rottler ex spreng. Journal of Medicinal Plants Studies, 7(2), 214-220.

Kapadia, S., Pudakalkatti, P. and Shivanaikar, S. (2015). Detection of antimicrobial activity of banana peel (Musa paradisiaca L.) on Porphyromonas gingivalis and Aggregatibacter actinomycetemcomitans: An in vitro study. Contemporary Clinical Dentistry, 6(4), 496-499. https://doi.org/10.4103/0976-237X.169864

Kossah, R., Nsabimana, C., Zhang, H. and Chen, W. (2010). Optimization of extraction of polyphenols from Syrian sumac (Rhus coriaria L.) and Chinese sumac (Rhus typhina L.) fruits. Research Journal of Phytochemistry, 4(3), 146-153. https:// doi.org/10.3923/rjphyto.2010.146.153

Le Bourvellec, C., Guyot, S. and Renard, C.M.G.C. (2009). Interactions between apple (Malus x domestica Borkh.) polyphenols and cell walls modulate the extractability of polysaccharides. Carbohydrate Polymers, 75(2), 251 -261. https://doi.org/10.1016/j.carbpol.2008.07.010

Mai, T.T., Thu, N.N., Tien, P.G. and Chuyen, N.V. (2007). Alpha-glucosidase inhibitory and antioxidant activities of Vietnamese edible plants and their relationships with polyphenol contents. Journal of Nutritional Science and Vitaminology, 53(3), 267276. https://doi.org/10.3177/jnsv.53.267

Nguyen, Q.-V., Nguyen, V.B., Eun, J.B., Wang, S.-L., Nguyen, D.H., Tran, T.N. and Nguyen, A.D. (2016). Anti-oxidant and antidiabetic effect of some medicinal plants belong to Terminalia species collected in Dak Lak Province, Vietnam. Research on Chemical Intermediates, 42(6), 5859-5871. https://doi.org/10.1007/s11164-015-2409-3

Nguyen, T.T., Pham, T.B., Thao, N.P., Dang, N.H., Nguyen, V.H., Pham, V.C., Minh, C.V., Tran, Q.H. and Dat, N.T. (2018). Phenolic Constituents from Fallopia multiflora (Thunberg) Haraldson. Journal of Chemistry, 2018, 4851439. https://doi.org/10.1155/2018/4851439

Nguyen, T.V. and Nguyen, H.T. (2019). Study on antibacterial effects of several Vietnamese medicine plants and their relationships with polyphenol contents. Asian Journal of Pharmaceutical and Clinical Research, 12(4), 257-265. https:// doi.org/10.22159/ajpcr.2019.v12i4.32290

Padayachee, A., Netzel, G., Netzel, M., Day, L., Zabaras, D., Mikkelsen, D. and Gidley, M.J. (2012). Binding of polyphenols to plant cell wall analogues - Part 1: Anthocyanins. Food Chemistry, 134(1), 155-161. https://doi.org/10.1016/j.foodchem.2012.02.082

Rebello, S., Asok, A.K., Mundayoor, S. and Jisha, M.S. (2014). Surfactants: Toxicity, remediation and green surfactants. Environmental Chemistry Letters, 12(2), 275-287. https://doi.org/10.1007/s10311-014-0466-2

Romelle, F.D., Rani, A. and Manohar, R.S. (2016). Chemical composition of some selected fruit peels. European Journal of Food Science and Technology, 4(4), 12-21.

Schmidt, M.M., Prestes, R.C., Kubota, E.H., Scapin, G. and Mazutti, M.A. (2015). Evaluation of antioxidant activity of extracts of banana inflorescences (Musa cavendishii). CyTA - Journal of Food, 13(4), 1-8. https://doi.org/10.1080/19476337.2015.1007532

Shengjiu, G., Kaimei, Z., Caizhen, L., Jiang, Y. and Yourui, X. (2014). Microwaves-assisted Extraction of Polyphenols from Banana Peel. Medicinal Plant, 5(1), 21-24.

Siddiqua, A., Premakumari, K.B., Sultana, R. and Sagar, D. (2010). Antioxidant activity and estimation of total phenolic content of muntingia calabura by colorimetry. International Journal of ChemTech Research, 2(1), 205-208.

Smeriglio, A., Barreca, D., Bellocco, E. and Trombetta, D. (2016). Chemistry, pharmacology and health benefits of anthocyanins: Anthocyanins and human health. Phytotherapy Research, 30(8), 1265-1286. https://doi.org/10.1002/ptr.5642

Tartrakoon, T., Chalearmsan, N., Vearasilp, T. and Meulen, U.T. (1999). The nutritive value of banana peel (Musa sapieutum L.) in growing pigs, presented at the Proceedings of the Deutscher Tropentag 1999. 
Berlin, Germany: Humboldt University of Berlin and ATSAF Berlin.

Thu, N.N., Sakurai, C., Uto, H., Chuyen, N.V., Lien, D.T.K., Yamamoto, S., Ohmori, R. and Kondo, K. (2004). The polyphenol content and antioxidant activities of the main edible vegetables in northern Vietnam. Journal of Nutritional Science and Vitaminology, 50(3), 203-210. https:// doi.org/10.3177/jnsv.50.203

Toor, R.K. and Savage, G.P. (2006). Effect of semidrying on the antioxidant components of tomatoes. Food Chemistry, 94(1), 90-97. https:// doi.org/10.1016/j.foodchem.2004.10.054

Veeresham, C. (2012). Natural products derived from plants as a source of drugs. Journal of Advanced Pharmaceutical Technology and Research, 3(4), 200 -201. https://doi.org/10.4103/2231-4040.104709

Yuksel, Z., Avci, E. and Erdem, Y.K. (2010). Characterization of binding interactions between green tea flavanoids and milk proteins. Food Chemistry, 121(2), 450-456. https://doi.org/10.1016/ j.foodchem.2009.12.064 